\title{
Planning Accelerated Life Tests for Burr Type X Failure Model with Type I Censoring
}

\author{
Nesar Ahmad \\ University Department of Statistics and Computer Applications \\ T. M. Bhagalpur University, Bhagalpur-812007, India \\ E-mail: nesar_bgp@yahoo.co.in \\ Sabiha Khan \\ Department of Public Health, Fiji School of Medicine, Suva, Fiji \\ M. G. M. Khan \\ School of Computing, Information and Mathematical Sciences, \\ The University of the South Pacific, Suva, Fiji \\ E-mail:khan_mg@usp.ac.fj \\ Received 6 June 2011 \\ Accepted 11 July 2013
}

\begin{abstract}
In this paper, we discuss the optimal accelerated life test plans for Burr type X distribution with log-linear model under periodic inspection and Type I censoring. We obtain the maximum likelihood estimators, the Fisher information and the asymptotic covariance matrix of the maximum likelihood estimators. Accelerated life test is optimized with respect to the low test stress and the proportion of test units allocated to the low test stress for given shape parameter. The asymptotic variance of the maximum likelihood estimator of qth quantile at the design stress is derived as an optimality criterion with equally spaced inspection times and the optimal allocation of units for two stress levels are determined. Optimality results show that the asymptotic variance of $q$ th quantile at the design stress is insensitive to the number of inspection times and to misspecifications of guessed failure probabilities at design and high test stresses. Procedures for planning an accelerated life test, including selection of sample size, have been discussed through an example.
\end{abstract}

Keywords: Accelerated life testing, Burr type X distribution, Maximum likelihood estimation, Type I censoring, Optimization techniques.

AMS 2000 Subject Classifications: 62N05.

Published by Atlantis Press

Copyright: the authors 


\section{Introduction}

There are many engineering situations where components in a system are designed to last a relatively long time under design conditions. These long life spans make it impractical to conduct life tests under design conditions. Accelerated life tests (ALTs) are used to estimate the lifetime of such highly reliable products within a reasonable testing time. In an ALT experiment, test units are run at higher than usual levels of stress to induce early failures. The test data obtained at the accelerated conditions are analyzed in terms of a model, and then extrapolated to the design stress to estimate the life distribution. Such ALTs have proven to be useful in many phases of product design and manufacture, from prototype testing to post production screening. Meeker and Escobar (1998) devoted three complete chapters to this topic and proper implementation of such tests. Nelson (1990) provided an extensive coverage of statistical models, test plans, and analytical procedures employed in accelerated life testing. For more details on research and issues in ALTs, see Meeker and Escobar (1993).

There are two inspection modes applied in ALT. One is the continuous inspection that results in exact failure times (see Chernoff (1962), Meeker (1984), Meeker and Nelson (1975), Nelson (1990), Nelson and Meeker (1978)). The other is the periodic inspection in which test units are inspected for failure at predetermined points in time. The periodic inspection is frequently employed by many authors (see Ahmad (2010), Ahmad and Islam (1996), Ahmad et al. (1994, 2006), Ehrenfeld (1962), Islam and Ahmad (1994), Meeker (1986), Yum and Choi (1989), Seo and Yum (1991)) because it requires less testing effort and is administratively more convenient. For more useful and up-to-date results in ALTs, see Nelson (2005), Yang (2007).

This paper considers planning ALT for items whose lifetime follows Burr type X failure model. Burr (1942) introduced twelve different form of cumulative distribution function for modeling lifetime data. Several authors consider different aspects of the Burr type X distribution (see Ahmad, et al. (1997), Jaheen (1996), Sartwi and Abu-Salih (1991), Raqab (1998), Surles and Padgett (1998, 2005), Raqab and Kundu (2005), Kundu and Raqab (2005)). Recently, Surles and Padgett (2001) and Ahmad, et al. (2009) showed that the Burr type $\mathrm{X}$ can be used quite effectively in reliability and survival analysis.

In this paper we develop ALT plans for the Burr type X distribution under Type I censoring and periodic inspection at two test stress levels. It is assumed that a log-linear model exists between the Burr type $\mathrm{X}$ scale parameter and the stresses and that the shape parameter is constant and is independent of the stresses. The unknown parameters in the log-linear model are estimated by maximum likelihood estimation (MLE) method. For the known shape parameter, the low test stress and associated proportion of test units are optimally determined at design stress. The optimal test plans are derived by minimizing the asymptotic variance of the maximum likelihood estimator of qth quantile at design stress. This paper is a generalization of Ahmad et al. (1994) work. It may also be viewed as an extension of Surles and Padgett (2001) work to the case of ALT with periodic inspection. A self-developed software program has been used to carry out the computations. The proposed method is limited to tests with only two acceleration levels, but we show it can be extended to multiple acceleration level situations.

Computational studies are conducted for various combinations of parameters to examine how the optimal plans vary with respect to these parameters at design and high-test stresses. Sensitivity analyses have also been performed for various combinations of parameters to assess the effect of inaccuracy to misspecification of guessed failure probabilities on the optimal plan at design and high-test stresses. Procedures for selecting a sample size and for planning an ALT are discussed with an example. 


\section{The Proposed Model and Test Method}

A statistical model for an ALT consists of a life distribution that represents the scatter in product life and a relationship between distribution parameter and accelerating stress. Most previous work on optimal design of ALT assumes that the life distribution is either exponential or Weibull (see Ahmad (2010), Ahmad et al. (1994), Chernoff (1953, 1962), Ehrenfeld (1962), Islam and Ahmad (1994), Meeker (1984), Meeker and Escobar (1998), Meeker and Nelson (1975), Nelson (1990), Nelson and Meeker (1978), Park and Yum (1996), Yum and Choi (1989), Seo and Yum (1991)). The Burr type XII, Burr type III, Normal and lognormal models have also been used (see Ahmad and Islam (1996), Ahmad et al. (2006), Meeker (1984), Nelson and Kielpinski (1976)). We propose the Burr type X lifetime distribution that describes the failure mechanism of test units.

\subsection{Assumptions}

We make the following assumptions:

- Three test stress levels $s_{0}, \mathrm{~s}_{1}, s_{2}$ are used such that $s_{0}<s_{1}<s_{2}$, where $s_{0}$ is the design stress level representing use condition and $s_{1}$ and $s_{2}$ are higher than usual stresses representing accelerated conditions.

- The lifetimes $(T)$ of test items at any stress $s$ follow the Burr type $X$ failure model. The probability density function of Burr type $\mathrm{X}$ failure model is given by

$$
f(t)=2(\sigma / \theta)(t / \theta) e^{-(t / \theta)^{2}}\left(1-e^{-(t / \theta)^{2}}\right)^{\sigma-1}, \quad t \geq 0
$$

where $\sigma>0$ is shape parameter and $\theta>0$ is a scale parameter.

The reliability function of $T$ is given by

$$
S(t)=1-\left(1-e^{-(t / \theta)^{2}}\right)^{\sigma},
$$

and the failure rate function is given by

$$
r(t)=\frac{2(\sigma / \theta)(t / \theta) e^{-(t / \theta)^{2}}\left(1-e^{-(t / \theta)^{2}}\right)^{\sigma-1}}{1-\left(1-e^{-(t / \theta)^{2}}\right)^{\sigma}} .
$$

Raqab and Kundu (2005) observed that for $\sigma \leq 1 / 2$ Burr type X density is a decreasing function and it is a right skewed unimodal function for $\sigma>1 / 2$. It also observed that Burr type X failure rates have the different shapes depending on the value of $\sigma$. For $\sigma>1 / 2$, it has increasing failure rate and for $\sigma \leq 1 / 2$, it is bathtub type. For more details properties of the Burr type X distribution, see Surles and Padgett (2005).

- The scale parameter $\theta$ is assumed to be a log-linear function of stress level $s$. That is,

$$
\ln \theta=\beta_{0}+\beta_{1} s,
$$

where $\beta_{0}$ and $\beta_{1}$ are unknown parameters to be estimated. The above relationship is frequently used in ALT. This model includes the inverse power model and the Arrhenius relation rate model see, Islam and Ahmad (1994), Nelson (1990).

Published by Atlantis Press

Copyright: the authors 
- The shape parameter $\sigma$ is independent of stresses (constant for any stress).

- The lifetimes of test units at stress level $s_{i}$ are independent and identically distributed.

\subsection{Test Procedure}

- The design stress $\left(s_{0}\right)$ and high-test stress $\left(s_{2}\right)$ are pre-specified, while the test stress $\left(s_{1}\right)$ is to be optimally determined.

- $\quad$ Out of total $N$ test items, the test items $\left(n_{i}\right)$ allocated to $s_{i}$ is given by

$$
\alpha_{i}=n_{i} / N, \alpha_{1}+\alpha_{2}=1 \text { and } N=n_{1}+n_{2} ; \quad \alpha_{i}>0, i=1,2
$$

where $\alpha_{1}$ is to be optimally determined.

- At stress level $s_{i}$, the test items $\left(n_{i}\right)$ are initially to be put on test and run until a pre-specified censoring time $t_{c i}$, see Fig. 1.

- The items are inspected periodically: at stress level $s_{i}$, at times $t_{i 1}, t_{i 2}, \ldots, t_{i K(i)}$, where $t_{i 0} \equiv 0, t_{i, K(i)+1} \equiv \infty$ and $t_{i, K(i)}$ is the Type I censoring time, denoted by $t_{c i}$, see Fig. 1 .

- At stress level $s_{i}$, the number of failures $x_{i j}$ and corresponding probability of failures $P_{i j}$ in the respective intervals $\left(t_{i, j-1}, t_{i j}\right)$ are recorded for $i=1,2$ and $j=1,2, \ldots, K(i)+1$, see Fig. 1 .

- The grouped data $\left\{x_{i j}, i=1,2 ; j=1,2, \ldots, K(i)+1\right\}$ are used to estimate $\beta_{0}$ and $\beta_{1}$ in (2). The estimated relationship is then extrapolated to estimate mean lifetime or $q$ th quantile at the design condition. At design condition $s_{0,}(2)$ can be written as

$$
\mu_{0}=\ln \theta_{0}=\beta_{0}+\beta_{1} s_{0} .
$$

Note that the $q$ th quantile $\left(t_{q}\right)$ of the lifetime distribution at design stress $s_{0}$ and $\mu_{0}$ are related as

$$
y_{q}=\ln t_{q}=\beta_{0}+\beta_{1} s_{0}+\frac{1}{2} \ln \left[-\ln \left(1-q^{1 / \sigma}\right)\right]
$$

Let $\hat{\beta}_{0}$ and $\hat{\beta}_{1}$ be the ML estimates of $\beta_{0}$ and $\beta_{1}$, respectively. Then,

$$
\begin{gathered}
\hat{\mu}_{0}=\hat{\beta}_{0}+\hat{\beta}_{1} s_{0}, \\
\text { and } \quad \hat{y}_{q}=\hat{\mu}_{0}+\frac{1}{2} \ln \left\{-\ln \left(1-q^{1 / \sigma}\right)\right\} .
\end{gathered}
$$

\subsection{Standardization}

Without loss of generality, let with and without prime represent the original and standardized scale, respectively, then the stress level is standardized as follows (see Meeker (1984)):

$s=\left(s^{\prime}-s_{0}^{\prime}\right) /\left(s_{2}^{\prime}-s_{0}^{\prime}\right)$,

Published by Atlantis Press

Copyright: the authors 
or equivalently,

$$
s^{\prime}=s\left(s_{2}^{\prime}-s_{0}^{\prime}\right)+s_{0}^{\prime},
$$

so that $0 \leq s \leq 1$, design stress $s_{0}=0$, and high stress $s_{2}=1$. We also standardized all the time related variables with respect to censoring time $t_{c}^{\prime} \quad\left(\right.$ say $t_{c 1}=t_{c 2}=t_{c}^{\prime}$ ). For instance, $t=t^{\prime} / t_{c}^{\prime}$ and $\theta=\theta^{\prime} / t_{c}^{\prime}$. Under the above standardization, the scale parameter is represented by $\theta=e^{\left(\beta_{0}^{\prime}+\beta_{1}^{\prime} s^{\prime}\right)} / t_{c}^{\prime}$. Because $\theta=e^{\left(\beta_{0}+\beta_{1} s\right)}$, we have

$$
\beta_{0}=\beta_{0}^{\prime}+\beta_{1}^{\prime} s_{0}^{\prime}-\ln t_{c}^{\prime}, \beta_{1}=\beta_{1}^{\prime}\left(s_{2}^{\prime}-s_{0}^{\prime}\right)
$$

Then from equation (7) it can be shown that

$$
\hat{y}_{q}^{\prime}=\hat{\beta}_{0}+\ln t_{c}^{\prime}+\frac{1}{2} \ln \left\{-\ln \left(1-q^{1 / \sigma}\right)\right\}
$$

Note that $t_{c}^{\prime}$ becomes 1 in the standardized time scale.

$$
\hat{y}_{q}^{\prime}=\hat{\beta}_{0}+\frac{1}{2} \ln \left\{-\ln \left(1-q^{1 / \sigma}\right)\right\}=\hat{y}_{q}
$$

Hence, no generality is lost under the above transformation.

\subsection{Optimization Criterion}

Nelson (1990) and Nelson and Kielpinski (1976) describe various criteria for determining optimal ALT plans. A common purpose of an ALT experiment is to estimate a particular quantile $t_{q}$ in the lower tail of the failure-time distribution at use conditions. Thus our optimality criterion is to minimize $\operatorname{As} \operatorname{Var}\left(\hat{y}_{q}\right)$, the asymptotic variance of the MLE of the logarithm of the target quantile at design conditions. $q$ is often chosen to be a small number like .01 or .001 .

\subsection{Design Problem}

The statistically optimal ALT plans under periodic inspection and Type I censoring can now be stated as: given $N, s_{0}, s_{2}, \sigma,\left\{t_{c i}\right\}_{i=1}^{2}$, and $\{K(i)\}_{i=1}^{2}$, determine $\alpha_{1}$ and $s_{1}$ such that the asymptotic variance, $\operatorname{As} \operatorname{Var}\left(\hat{y}_{q}\right)$, is minimized using equally spaced inspection times.

The design problem of an ALT under periodic inspection and Type I censoring may be extended to $l$ stress levels and can be stated as: given $N, s_{0}, s_{1}, \sigma,\left\{t_{c i}\right\}_{i=1}^{l}$, and $\{K(i)\}_{i=1}^{l}$, determine $\left\{\alpha_{i}\right\}_{i=1}^{l-1}$ and $\left\{s_{i}\right\}_{i=1}^{l-1}$ such that the $\operatorname{As} \operatorname{Var}\left(\hat{y}_{q}\right)$ is minimized using equally spaced inspection times. 


\section{Estimation of Parameters}

There are several methods of estimation for censored data, which provide estimates of the parameters of the assumed log-linear model. The MLE method is used for the following reasons (see Ahmad and Islam (1996), Meeker and Nelson (1975), Nelson (1990)).

- It is easier to calculate the optimal plans by this method in comparison to linear estimation methods.

- This method provides asymptotically minimum variance estimates for large sample sizes. Also, for small sample sizes, ML estimates generally compare well with other estimates.

\subsection{Maximum Likelihood Estimation}

The likelihood function of the set of observations $\left\{x_{i j}\right\}_{j=1}^{K(i)+1}$ which are multinomially distributed with $n_{i}$ and $\left\{P_{i j}\right\}_{j=1}^{K(i)+1}$ at stress level $s_{i}$, is given by

$$
L^{\prime}=\prod_{i=1}^{2} L_{i}^{\prime}=\prod_{i=1}^{2} n_{i} !\left(\prod_{j=1}^{K(i)+1} x_{i j} !\right)^{-1}\left(\prod_{j=1}^{K(i)+1} P_{i j}^{x_{i j}}\right)
$$

Taking logarithm of both the sides, we get

$$
L=\ln L^{\prime}=\sum_{i=1}^{2} \ln L_{i}^{\prime}=C+\sum_{i=1}^{2} \sum_{j=1}^{K(i)+1} x_{i j} \ln P_{i j}
$$

where $C$ is constant with respect to $\beta_{0}$ and $\beta_{1}$ and

$$
P_{i j}=\left[1-e^{-\left(t_{i j} / \theta_{i}\right)^{2}}\right]^{\sigma}-\left[1-e^{-\left(t_{i, j-1} / \theta_{i}\right)^{2}}\right]^{\sigma} \text {, for } i=1,2 \text { and } j=1,2, \ldots \ldots, K(i)+1
$$

The ML estimates of $\beta_{0}$ and $\beta_{1}$ can be obtained by solving the following equations:

$$
\frac{\partial L}{\partial \beta_{0}}=0 \text { and } \frac{\partial L}{\partial \beta_{1}}=0
$$

The above equations can be rewritten as

$$
\begin{gathered}
\frac{\partial L}{\partial \beta_{0}}=\sum_{i=1}^{2} \sum_{j=1}^{K(i)+1}\left\{x_{i j}\left(A_{i, j-1}-A_{i j}\right) / P_{i j}\right\}=0, \\
\frac{\partial L}{\partial \beta_{1}}=\sum_{i=1}^{2} s_{i} \sum_{j=1}^{K(i)+1}\left\{x_{i j}\left(A_{i, j-1}-A_{i j}\right) / P_{i j}\right\}=0, \\
\text { Published by Atlantis Press } \\
\text { Copyright: the authors }
\end{gathered}
$$


where $\quad A_{i j}=2 \sigma\left(t_{i j} / \theta_{i}\right)^{2} e^{-\left(t_{i j} / \theta_{i}\right)^{2}}\left(1-e^{-\left(t_{i j} / \theta_{i}\right)^{2}}\right)^{\sigma-1}$, for $i=1,2$ and $j=0,1,2, \ldots, K(i)+1$.

\subsection{Fisher Information Matrix}

The Fisher information matrix $F$ (see Nelson (1990), Rao (1973)) for the optimal plan is

$$
F=\left[\begin{array}{cc}
\sum_{i=1}^{2} E\left(-\frac{\partial^{2} \ln L_{i}^{\prime}}{\partial \beta_{0}^{2}}\right) & \sum_{i=1}^{2} E\left(-\frac{\partial^{2} \ln L_{i}^{\prime}}{\partial \beta_{0} \partial \beta_{1}}\right) \\
\sum_{i=1}^{2} E\left(-\frac{\partial^{2} \ln L_{i}^{\prime}}{\partial \beta_{1} \partial \beta_{0}}\right) & \sum_{i=1}^{2} E\left(-\frac{\partial^{2} \ln L_{i}^{\prime}}{\partial \beta_{1}^{2}}\right)
\end{array}\right]=N\left(f_{g h}\right), \quad g, h,=0,1,
$$

where $\quad f_{g h}=\sum_{i=1}^{2} \alpha_{i} \sum_{j=1}^{K(i)+1}\left(\frac{\partial P_{i j}}{\partial \beta_{g}}\right)\left(\frac{\partial P_{i j}}{\partial \beta_{h}}\right) / P_{i j}$.

After some algebraic simplification, (14) becomes

$$
f_{g h}=\sum_{i=1}^{2} \alpha_{i} s_{i}^{(g+h)} Q_{i} \quad, \text { for } g, h=0,1,
$$

where

$$
Q_{i}=\sum_{j=1}^{K(i)+1}\left(A_{i, j-1}-A_{i j}\right)^{2} / P_{i j} \quad, \quad \text { for } i=1,2
$$

Note that

$$
\frac{\partial P_{i j}}{\partial \beta_{1}}=s_{i} \frac{\partial P_{i j}}{\partial \beta_{0}}
$$

\subsection{Asymptotic Variances of MLEs}

The asymptotic covariance matrix $V$ of the ML estimates $\hat{\beta}_{0}$ and $\hat{\beta}_{1}$ is the inverse of the Fisher information matrix $F$ :

$$
V=F^{-1}=\left[\begin{array}{ll}
A s \operatorname{Var}\left(\hat{\beta}_{0}\right) & A s \operatorname{Cov}\left(\hat{\beta}_{0}, \hat{\beta}_{1}\right) \\
A s \operatorname{Cov}\left(\hat{\beta}_{1}, \hat{\beta}_{0}\right) & A s \operatorname{Var}\left(\hat{\beta}_{1}\right)
\end{array}\right]=\frac{1}{N}\left(f_{g h}\right)^{-1}, g, h=0,1 .
$$

The asymptotic variance (AsVar) of the MLE of $\hat{y}_{q}$ is 


$$
\begin{aligned}
\operatorname{As} \operatorname{Var}\left(\hat{y}_{q}\right) & =\left(1, s_{0}\right) V\left(1, s_{0}\right)^{\prime} \\
& =N^{-1}\left(f_{00} f_{11}-f_{01}^{2}\right)^{-1}\left(f_{11}+s_{0}^{2} f_{00}-2 s_{0} f_{01}\right) .
\end{aligned}
$$

\section{Optimal Plans}

\subsection{Optimization Method}

The optimal plans are determined with the following simplified assumptions and standardization:

- Censoring times at $\mathrm{s}_{1}$ and $s_{2}$ are the same, that is, $t_{c 1}=t_{c 2}=t_{c}$.

- The number of inspections at each stress level is the same, that is, $K(1)=K(2)=K$ (known).

- Parameters are standardized such that the common censoring time, as well as the high test stress becomes 1 , and the design stress is 0 . That is, $t_{c}=s_{2}=1$, and $s_{0}=0$. Such standardization does not alter the nature of our problem.

Based upon the above assumptions and standardization, (19) is reduced to

$$
\begin{aligned}
\operatorname{As} \operatorname{Var}\left(\hat{y}_{q}\right) & =\operatorname{As} \operatorname{Var}\left(\hat{\beta}_{0}\right) \\
& =N^{-1}\left(f_{00} f_{11}-f_{01}^{2}\right)^{-1} f_{11}
\end{aligned}
$$

After some algebraic simplification (20) becomes

$$
\operatorname{As} \operatorname{Var}\left(\hat{y}_{q}\right)=N^{-1}\left(s_{1}^{2} Q_{1} \alpha_{1}+Q_{2}\left(1-\alpha_{1}\right)\right) /\left(Q_{1} Q_{2}\left(s_{1}-1\right)^{2}\left(-\alpha_{1}^{2}+\alpha_{1}\right)\right)
$$

or

$$
\operatorname{As} \operatorname{Var}\left(\hat{y}_{q}\right)=\frac{s_{2}^{2}}{\alpha_{1} N Q_{1}\left(s_{1}-s_{2}\right)^{2}}+\frac{s_{1}^{2}}{\alpha_{2} N Q_{2}\left(s_{1}-s_{2}\right)^{2}}
$$

Under the above assumptions, the optimal plan is developed by determining optimal values of $s_{1}$ and $\alpha_{1}$, say $s_{1}^{*}$ and $\alpha_{1}^{*}$ respectively, for given $N, K$, and $\sigma$ by minimizing $A s \operatorname{Var}\left(\hat{y}_{q}\right)$. This asymptotic variance depends on the unknown quantities $\beta_{0}$ and $\beta_{1}$, which are expressible in terms of the more approachable parameters $P_{u}$ and $P_{h}$, where

$$
P_{u}=P_{s_{0}}\left(T<t_{c}\right)
$$

the probability that an item under design stress would fail before the censoring time and

$$
P_{h}=P_{s_{2}}\left(T<t_{c}\right),
$$


the probability that an item under high test stress would fail before the censoring time. From expert judgment the user supplies $P_{u}$ and $P_{h}$, which determines $\beta_{0}$ and $\beta_{1}$. That is

$$
\beta_{0}=\frac{1}{2} \ln \left(-1 / \ln \left(1-P_{u}^{1 / \sigma}\right)\right)
$$

and

$$
\beta_{1}=\frac{1}{2} \ln \left(\ln \left(1-P_{u}^{1 / \sigma}\right) / \ln \left(1-P_{h}^{1 / \sigma}\right)\right)
$$

For given values of $K, P_{u}, P_{h}$, and $\sigma$, optimal values of $s_{1}$ and $\alpha_{1}$ are determined by the following two-step procedure that minimizes $A s \operatorname{Var}\left(\hat{y}_{q}\right)$.

- We obtain the optimum values of $\alpha_{i}(i=1,2)$ by formulating the problem as the following nonlinear programming problem (NLPP):

$$
\begin{array}{ll}
\text { Minimize } & Z=\sum_{i=1}^{2} \frac{A_{i}}{\alpha_{i}} \\
\text { subject to } & \sum_{i=1}^{2} \alpha_{i}=1, \\
\text { and } & \alpha_{i}>0, i=1,2
\end{array}
$$

where $A_{1}=\frac{s_{2}^{2}}{N Q_{1}\left(s_{1}-s_{2}\right)^{2}}$ and $A_{2}=\frac{s_{1}^{2}}{N Q_{2}\left(s_{1}-s_{2}\right)^{2}}$.

The restrictions $\alpha_{i}>0$ are obvious because negative values of $\alpha_{i}$ are of no practical use.

Ignoring the restrictions $\alpha_{i}>0$, we can use Lagrange multipliers technique to solve NLPP (25) for determining the optimum values of $\alpha_{i}$. If these values (say) $\alpha_{i}^{*}$, satisfy the ignored restrictions, the NLPP (25) is solved completely.

The Lagrangian function $\varphi$ is defined as

$$
\varphi\left(\alpha_{i}, \lambda\right)=\sum_{i=1}^{2} \frac{A_{i}}{\alpha_{i}}+\lambda\left(\sum_{i=1}^{2} \alpha_{i}-1\right)
$$

where $\lambda$ is a Lagrange multiplier.

The necessary conditions for the solution of the problem are 


$$
\frac{\partial L}{\partial \alpha_{i}}=-\frac{A_{i}}{\alpha_{i}^{2}}+\lambda=0
$$

which gives

and

$$
\alpha_{i}=\sqrt{\frac{A_{i}}{\lambda}} ; \quad i=1,2
$$

Solving (27) and (28) the optimum solution to NLPP (25) is given by

$$
\alpha_{1}^{*}=\frac{s_{2}}{\sqrt{\left(s_{1}^{2} Q_{1}+s_{2}^{2} Q_{2}\right) / Q_{2}}} \text { and } \alpha_{2}^{*}=1-\alpha_{1}^{*} \text {. }
$$

It can be verified that the objective function $Z$ in (25) is convex and the constraint is linear. Therefore, the Kuhn-Tucker necessary conditions for the NLPP (25), which are also sufficient for the problem, are hold at the point $\left(\alpha_{1}^{*}, \alpha_{2}^{*}\right)$ given by (29). Hence, $\left(\alpha_{1}^{*}, \alpha_{2}^{*}\right)$ is optimum for NLPP (25).

- We imply a grid search with respect to $s_{1}$. We divide the range of standardized stress into 500 equal parts, and calculate $\alpha_{1}^{*}$ and $A \operatorname{Var}\left(\hat{y}_{q}\right)$ at each grid point, $0.000,0.002,0.004, \ldots, 0.998$. Among these grid points we select the one that yields the smallest value of $\operatorname{As} \operatorname{Var}\left(\hat{y}_{q}\right)$.

When $K$ tend to infinity (i.e. continuous inspection) the minimum $\operatorname{As} \operatorname{Var}\left(\hat{y}_{q}\right)$ and corresponding $s_{1}^{*}$ and $\alpha_{1}^{*}$ are determined by using the method described by Nelson and Meeker (1978). It can also be determined by a two-step procedure. Finally, the ratio of $\operatorname{As} \operatorname{Var}\left(\hat{y}_{q}(K)\right)$ to $\operatorname{As} \operatorname{Var}\left(\hat{y}_{q}(\infty)\right)$ is determined, A FORTRAN coded algorithm finds $\left(s_{1}, \alpha_{1}\right)$ that minimizes the $\operatorname{As} \operatorname{Var}\left(\hat{y}_{q}\right)$ has been written and was run on the computer.

\subsection{Sensitivity Analysis}

To use an optimal plan, one must provide approximate values of the model parameters (or equivalently $P_{u}$ and $\left.P_{h}\right)$. Chernoff $(1953,1962)$ call such a plan "locally optimal". Values that are appreciable in error may result in a plan that is far from optimal. This possibility can be checked if one examines the plans for different parameter values and suggested sensitivity analysis. For some selected values of $P_{u}, P_{h}$, and $\sigma$, a sensitivity analysis was conducted to see how misspecification of imputed failure probabilities affect $\operatorname{As} \operatorname{Var}\left(\hat{y}_{q}\right)$. Let $\widetilde{P}_{u}$ and $\widetilde{P}_{h}$ be the guessed values of imputed failure probabilities. For these guessed 
values optimal $s_{1}$ (i.e. $\left.\widetilde{s}_{1}^{*}\right)$ and $\alpha_{1}$ (i.e. $\left.\widetilde{\alpha}_{1}^{*}\right)$ are determined. The ratio of $\operatorname{As} \operatorname{Var}\left(\hat{y}_{q}\left(\tilde{s}_{1}^{*}, \tilde{\alpha}_{1}^{*}\right)\right)$ to minimum $\operatorname{As} \operatorname{Var}\left(\hat{y}_{q}\left(s_{1}^{*}, \alpha_{1}^{*}\right)\right)$ is calculated for various cases with $K=2$.

\subsection{Sample size}

From (21), we observe that $N$ appears in $\operatorname{As} \operatorname{Var}\left(\hat{y}_{q}\right)$ as a scaling factor only; therefore, $s_{1}{ }^{*}$ and $\alpha_{1}^{*}$ do not depend on $N$. However, $N$ affects the magnitude of $A s \operatorname{Var}\left(\hat{y}_{q}\right)$, implying the need for its selection.

To determine the sample size $N$, one requires that with high probability $\phi, \hat{\theta}_{0}$ falls between $\theta_{0} / h$ and $\theta_{0} h$ for a specified $h(>1)$ (see Meeker, (1986)). That is

$$
P_{r}\left\{\theta_{0} / h \leq \hat{\theta}_{0} \leq \theta_{0} h\right\} \geq \phi
$$

Note that (30) can be rewritten as

$$
P_{r}\left\{\mu_{0}-\ln h \leq \hat{\mu}_{0} \leq \mu_{0}+\ln h\right\} \geq \phi
$$

Then, the approximate sample size is obtained as

$$
N^{*} \cong \frac{\mathrm{v}_{0} \omega^{2}}{(\ln h)^{2}},
$$

where $v_{0}$ is the asymptotic variance of $\hat{\mu}_{0}$ when $N=1$ and $\omega$ is the $(1+\phi) / 2$ quantile of the standard normal distribution.

\section{Optimality Results}

Optimal ALT results are presented in Tables 1-2 for various combinations of $P_{u}, P_{h}, K$, and $\sigma$. Tables 3-4 summarize results of sensitivity analysis for various values of $P_{u}, P_{h}$, and $\sigma$ with $K=2$. We have the following observations:

- $\quad$ For given values of $P_{u}, P_{h}$, and $\sigma, \operatorname{As} \operatorname{Var}\left(\hat{y}_{q}\right)$ is almost same over the number of inspection $(K)$. Thus increasing $K$ has little effect on the asymptotic variance. This implies that the number of inspection need not be too large.

- $\quad$ For given value of $\sigma, \operatorname{As} \operatorname{Var}\left(\hat{y}_{q}\right)$ is insensitive to $K$ as $P_{u}$ increases and/or $P_{h}$ decreases.

- In all cases, the values of ratio in last column of tables indicate that there is no significant difference in $\operatorname{As} \operatorname{Var}\left(\hat{y}_{q}\right)$ for variation in $K$, because it is much closer to 1 . Therefore, unnecessarily large $K$ is not needed, which is an encouraging result in terms of testing efforts.

- When $P_{u}$ and $P_{h}$ are fixed, $s_{1}^{*}$ and $\alpha_{1}^{*}$ are fairly stable over $K$ in all the cases under study. 
- $\quad$ For selected values of $\sigma$ and $P_{u}$, as $P_{h}$ decreases, asymptotic variance of $\hat{\mu}_{0}$ increases and it become minimum when $P_{h}$ is 0.99 .

- For selected values of $\sigma$ and $P_{h}$, as $P_{u}$ increases, $\operatorname{As} \operatorname{Var}\left(\hat{y}_{q}\right)$ decreases and it become minimum when $P_{u}$ equals 0.1 .

- In general, for given $\sigma, s_{1}^{*}$ gets close to zero (the design stress) and $\alpha_{1}^{*}$ to 1 , as $P_{u}$ increases and/or $P_{h}$ decreases. For instance, when $P_{u}=0.1$ and $P_{h} \leq 0.99, s_{1}^{*} \cong 0$ and $\alpha_{1}^{*} \cong 1$. Similar trends are also observed when $P_{u}$ is less than 0.1 , for small values of $P_{h}$. This implies that there is almost no need for an ALT.

- $\quad$ For each $P_{u}$ and $P_{h}$, asymptotic variance of $\hat{\mu}_{0}$ decreases as $\sigma$ increases.

- For given $\sigma$, ratio values of sensitivity analysis indicate that the plan is robust against the likely departures of the true $P_{u}$ and $P_{h}$ from their guessed values for all $K$.

- The results of optimal plans obtained by Ahmad et al. (1994) becomes the particular case of the result obtained here for $\sigma=1$ (Table 1).

\section{Planning ALTs}

We suggest the following procedure for planning an ALT.

- $\quad$ Provide pre-estimates of $P_{u}, P_{h}$, and $\sigma$ and the ranges of their plausible values.

- Determine an optimal test plan using the pre-estimates.

- $\quad$ For given $\sigma$, conduct sensitivity analyses with respect to the plausible values of pre-estimates.

- $\quad$ Check the necessity of an ALT based upon $s_{1}^{*}$ and $\alpha_{1}^{*}$.

- $\quad$ Determine the sample size. 
Table 1. Optimal ALT Plans when $\sigma=1.0$.

\begin{tabular}{|c|c|c|c|c|c|c|c|c|}
\hline$P_{u}$ & $P_{h}$ & $\beta_{0}$ & $\beta_{1}$ & $K$ & $s_{1}^{*}$ & $\alpha_{1}^{*}$ & $N \operatorname{As} \operatorname{Var}\left(\hat{y}_{q}\right)$ & Ratio \\
\hline \multirow[t]{20}{*}{0.0001} & 0.99 & 4.605 & -5.369 & 2 & 0.698 & 0.752 & 29.483 & 1.0744 \\
\hline & & & & 5 & 0.706 & 0.765 & 27.808 & 1.0134 \\
\hline & & & & 10 & 0.706 & 0.768 & 27.529 & 1.0032 \\
\hline & & & & $\infty$ & 0.706 & 0.770 & 27.441 & 1 \\
\hline & 0.9 & 4.605 & -5.022 & 2 & 0.708 & 0.787 & 41.060 & 1.0283 \\
\hline & & & & 5 & 0.710 & 0.794 & 40.114 & 1.0047 \\
\hline & & & & 10 & 0.710 & 0.795 & 39.373 & 1.0011 \\
\hline & & & & $\infty$ & 0.710 & 0.796 & 39.928 & 1 \\
\hline & 0.5 & 4.605 & -4.422 & 2 & 0.698 & 0.823 & 86.461 & 1.0029 \\
\hline & & & & 5 & 0.698 & 0.824 & 86.254 & 1.0005 \\
\hline & & & & 10 & 0.698 & 0.824 & 86.221 & 1.0001 \\
\hline & & & & $\infty$ & 0.698 & 0.824 & 86.211 & 1 \\
\hline & 0.1 & 4.605 & -3.480 & 2 & 0.630 & 0.849 & 317.219 & 1.0001 \\
\hline & & & & 5 & 0.630 & 0.849 & 317.203 & 1.0000 \\
\hline & & & & 10 & 0.630 & 0.849 & 317.200 & 1.0000 \\
\hline & & & & $\infty$ & 0.630 & 0.849 & 317.200 & 1 \\
\hline & 0.01 & 4.605 & -2.305 & 2 & 0.444 & 0.890 & 1318.717 & 1.0000 \\
\hline & & & & 5 & 0.444 & 0.890 & 1318.716 & 1.0000 \\
\hline & & & & 10 & 0.444 & 0.890 & 1318.716 & 1.0000 \\
\hline & & & & $\infty$ & 0.444 & 0.890 & 1318.716 & 1 \\
\hline \multirow[t]{16}{*}{0.001} & 0.99 & 3.454 & -4.217 & 2 & 0.616 & 0.774 & 17.141 & 1.0676 \\
\hline & & & & 5 & 0.624 & 0.787 & 16.252 & 1.0122 \\
\hline & & & & 10 & 0.626 & 0.789 & 16.103 & 1.0029 \\
\hline & & & & $\infty$ & 0.626 & 0.790 & 16.056 & 1 \\
\hline & 0.9 & 3.454 & -3.871 & 2 & 0.620 & 0.809 & 23.131 & 1.0256 \\
\hline & & & & 5 & 0.624 & 0.814 & 22.649 & 1.0042 \\
\hline & & & & 10 & 0.624 & 0.815 & 22.577 & 1.0010 \\
\hline & & & & $\infty$ & 0.624 & 0.816 & 22.555 & 1 \\
\hline & 0.5 & 3.454 & -3.270 & 2 & 0.590 & 0.847 & 44.774 & 1.0025 \\
\hline & & & & 5 & 0.592 & 0.846 & 44.681 & 1.0004 \\
\hline & & & & 10 & 0.592 & 0.846 & 44.666 & 1.0001 \\
\hline & & & & $\infty$ & 0.592 & 0.846 & 44.662 & 1 \\
\hline & 0.1 & 3.454 & -2.328 & 2 & 0.446 & 0.888 & 129.820 & 1.0000 \\
\hline & & & & 5 & 0.446 & 0.888 & 129.815 & 1.0000 \\
\hline & & & & 10 & 0.446 & 0.888 & 129.814 & 1.0000 \\
\hline & & & & $\infty$ & 0.446 & 0.888 & 129.813 & 1 \\
\hline \multirow[t]{12}{*}{0.01} & 0.99 & 2.300 & -3.064 & 2 & 0.472 & 0.817 & 8.113 & 1.0547 \\
\hline & & & & 5 & 0.484 & 0.826 & 7.768 & 1.0099 \\
\hline & & & & 10 & 0.486 & 0.828 & 7.710 & 1.0024 \\
\hline & & & & $\infty$ & 0.486 & 0.829 & 7.692 & 1 \\
\hline & 0.9 & 2.300 & -2.717 & 2 & 0.458 & 0.852 & 10.293 & 1.0200 \\
\hline & & & & 5 & 0.464 & 0.855 & 10.125 & 1.0033 \\
\hline & & & & 10 & 0.466 & 0.855 & 10.099 & 1.0008 \\
\hline & & & & $\infty$ & 0.466 & 0.855 & 10.091 & 1 \\
\hline & 0.5 & 2.300 & -2.117 & 2 & 0.368 & 0.898 & 16.644 & 1.0017 \\
\hline & & & & 5 & 0.368 & 0.899 & 16.621 & 1.0003 \\
\hline & & & & 10 & 0.368 & 0.899 & 16.617 & 1.0001 \\
\hline & & & & $\infty$ & 0.368 & 0.899 & 16.616 & 1 \\
\hline
\end{tabular}


Table 2. Optimal ALT Plans when $\sigma=1.5$.

\begin{tabular}{|c|c|c|c|c|c|c|c|c|}
\hline$P_{u}$ & $P_{h}$ & $\beta_{0}$ & $\beta_{1}$ & $K$ & $s_{1}^{*}$ & $\alpha_{1}^{*}$ & $N \operatorname{As} \operatorname{Var}\left(\hat{y}_{q}\right)$ & Ratio \\
\hline \multirow[t]{20}{*}{0.0001} & \multirow[t]{4}{*}{0.99} & \multirow[t]{4}{*}{3.070} & \multirow[t]{4}{*}{-3.875} & 2 & 0.652 & 0.742 & 12.988 & 1.0889 \\
\hline & & & & 5 & 0.660 & 0.757 & 12.134 & 1.0173 \\
\hline & & & & 10 & 0.662 & 0.760 & 11.977 & 1.0042 \\
\hline & & & & $\infty$ & 0.662 & 0.761 & 11.927 & 1 \\
\hline & \multirow[t]{4}{*}{0.9} & \multirow[t]{4}{*}{3.070} & \multirow[t]{4}{*}{-3.564} & 2 & 0.668 & 0.776 & 18.386 & 1.0430 \\
\hline & & & & 5 & 0.672 & 0.785 & 17.753 & 1.0071 \\
\hline & & & & 10 & 0.674 & 0.785 & 17.658 & 1.0017 \\
\hline & & & & $\infty$ & 0.674 & 0.785 & 17.628 & 1 \\
\hline & \multirow[t]{4}{*}{0.5} & \multirow[t]{4}{*}{3.070} & \multirow[t]{4}{*}{-3.067} & 2 & 0.672 & 0.815 & 38.683 & 1.0064 \\
\hline & & & & 5 & 0.674 & 0.815 & 38.478 & 1.0011 \\
\hline & & & & 10 & 0.674 & 0.816 & 38.445 & 1.0003 \\
\hline & & & & $\infty$ & 0.674 & 0.816 & 38.435 & 1 \\
\hline & \multirow[t]{4}{*}{0.1} & \multirow[t]{4}{*}{3.070} & \multirow[t]{4}{*}{-2.361} & 2 & 0.620 & 0.845 & 141.717 & 1.0003 \\
\hline & & & & 5 & 0.620 & 0.845 & 141.680 & 1.0001 \\
\hline & & & & 10 & 0.620 & 0.845 & 141.674 & 1.0000 \\
\hline & & & & $\infty$ & 0.620 & 0.845 & 141.672 & 1 \\
\hline & \multirow[t]{4}{*}{0.01} & \multirow[t]{4}{*}{3.070} & \multirow[t]{4}{*}{-1.546} & 2 & 0.442 & 0.889 & 588.183 & 1.0000 \\
\hline & & & & 5 & 0.442 & 0.889 & 588.179 & 1.0000 \\
\hline & & & & 10 & 0.442 & 0.889 & 588.178 & 1.0000 \\
\hline & & & & $\infty$ & 0.442 & 0.889 & 588.178 & 1 \\
\hline \multirow[t]{16}{*}{0.001} & \multirow[t]{4}{*}{0.99} & \multirow[t]{4}{*}{2.300} & \multirow[t]{4}{*}{-3.106} & 2 & 0.566 & 0.768 & 7.782 & 1.0801 \\
\hline & & & & 5 & 0.576 & 0.781 & 7.318 & 1.0156 \\
\hline & & & & 10 & 0.578 & 0.784 & 7.232 & 1.0038 \\
\hline & & & & $\infty$ & 0.578 & 0.785 & 7.205 & 1 \\
\hline & 0.9 & 2.300 & -2.795 & 2 & 0.578 & 0.799 & 10.621 & 1.0385 \\
\hline & & & & 5 & 0.582 & 0.808 & 10.293 & 1.0064 \\
\hline & & & & 10 & 0.584 & 0.808 & 10.243 & 1.0015 \\
\hline & & & & $\infty$ & 0.584 & 0.809 & 10.228 & 1 \\
\hline & 0.5 & 2.300 & -2.297 & 2 & 0.562 & 0.841 & 20.412 & 1.0056 \\
\hline & & & & 5 & 0.564 & 0.841 & 20.318 & 1.0010 \\
\hline & & & & 10 & 0.564 & 0.841 & 20.303 & 1.0002 \\
\hline & & & & $\infty$ & 0.564 & 0.841 & 20.298 & 1 \\
\hline & 0.1 & 2.300 & -1.592 & 2 & 0.436 & 0.886 & 58.627 & 1.0002 \\
\hline & & & & 5 & 0.436 & 0.886 & 58.615 & 1.0000 \\
\hline & & & & 10 & 0.436 & 0.886 & 58.613 & 1.0000 \\
\hline & & & & $\infty$ & 0.436 & 0.886 & 58.612 & 1 \\
\hline 0.01 & 0.99 & 1.523 & -2.329 & 2 & 0.422 & 0.816 & 3.871 & 1.0640 \\
\hline & & & & 5 & 0.434 & 0.826 & 3.684 & 1.0126 \\
\hline & & & & 10 & 0.436 & 0.828 & 3.649 & 1.0030 \\
\hline & & & & $\infty$ & 0.438 & 0.828 & 3.638 & 1 \\
\hline & 0.9 & 1.523 & -2.018 & 2 & 0.414 & 0.848 & 4.930 & 1.0297 \\
\hline & & & & 5 & 0.422 & 0.853 & 4.811 & 1.0050 \\
\hline & & & & 10 & 0.424 & 0.853 & 4.793 & 1.0012 \\
\hline & & & & $\infty$ & 0.424 & 0.853 & 4.787 & 1 \\
\hline & 0.5 & 1.523 & -1.520 & 2 & 0.340 & 0.897 & 7.841 & 1.0038 \\
\hline & & & & 5 & 0.340 & 0.898 & 7.817 & 1.0007 \\
\hline & & & & 10 & 0.340 & 0.898 & 7.813 & 1.0002 \\
\hline & & & & $\infty$ & 0.342 & 0.897 & 7.811 & 1 \\
\hline
\end{tabular}

\section{An Application}

Suppose that an experimenter is planning to develop an ALT for a certain type of electrical capacitor with the use of temperature (or voltage) as an accelerating stress. The lifetimes of electrical capacitors are 
known to have a Burr type $\mathrm{X}$ failure distribution, and the log mean lifetime at the design stress is of interest. The design stress is characterized by $30^{\circ} \mathrm{C}$ (or $20 \mathrm{~V}$ ). The high stress level of temperature (or voltage) is pre-specified as $120^{\circ} \mathrm{C}$ (or $400 \mathrm{~V}$ ). The test duration (the censoring time $t_{c}$ ) is allowed for 1000 hours at each stress level. The experimenter first guesses the $P_{u}, P_{h}$ and $\sigma$ is $0.0001,0.90$ and 1.5, respectively.

Based upon the above information the optimal plan for $K=2$ are computed to be (see Table 2):

$\beta_{0}=3.070, \beta_{1}=-3.564, s_{1}^{*}=0.668, \alpha_{1}^{*}=0.776$, and $N . \operatorname{As} \operatorname{Var}\left(\hat{y}_{q}\right)=18.386$.

Now, we want to calculate sample size by taking $\phi$ and $h$ as 0.9 and 2.0, respectively. Using (32), the required sample size becomes approximately 104. Being conservative, the experimenter might want to determine the sample size for the worst case of this optimal plan where $\operatorname{As} \operatorname{Var}\left(\hat{y}_{q}\right)=588.183$ for $P_{h}=$ 0.01 and same $P_{u}, \sigma$, and $K$. We obtain a conservative sample size 3318 .

Next, the experimenter guesses that $P_{u}, P_{h}$ and $\sigma$ are $0.0001,0.90$ and 1, respectively, then the optimal plan for $K=2$ are computed as (see Table 1):

$$
\beta_{0}=4.605, \beta_{1}=-5.022, s_{1}^{*}=0.708, \alpha_{1}^{*}=0.787 \text {, and } N . A s \operatorname{Var}\left(\hat{y}_{q}\right)=41.060 \text {. }
$$

For the same $\phi$ and $h$, an approximate sample size obtained for this optimal plan is 232 . Hence, if the shape parameter decreases an experimenter requires larger sample size.

Although the true values of $P_{u}$ and $P_{h}$ are different from their guessed values, suppose that the ranges of the plausible values of $P_{u}, P_{h}$, and $\sigma$ are as follows:

$$
\begin{gathered}
0.00001 \leq \tilde{P}_{u} \leq 0.05, \\
0.006 \leq \tilde{P}_{h} \leq 0.999, \\
1 \leq \sigma \leq 2 .
\end{gathered}
$$

For the above plausible ranges of pre-estimates, sensitivity analyses are conducted. Tables 3-4 shows that sensitivity ratios are very close to 1 , implying that the selected plan in (33) is generally robust against the likely departures of true $P_{u}, P_{h}$, and $\sigma$ from their guessed values, except for the case where $P_{u}$ is underestimated and $P_{h}$ is overestimated. For instance, using the guessed values of $P_{u}=0.0001, P_{h}=0.90$, , and $\sigma=1.5$ as $\tilde{P}_{u}=0.0003, \tilde{P}_{h}=0.70$, and $\sigma=1.5$ (see Table 4) then the optimal plan for $K=2$ has relatively increased in $\operatorname{As} \operatorname{Var}\left(\hat{y}_{q}\right)$. The sensitivity is 1.0220 which means that the increase in $A s \operatorname{Var}\left(\hat{y}_{q}\right)$ due to the uncertainties involved in estimating $P_{u}, P_{h}$, and $\sigma$ is $2.20 \%$. Also, the sensitivity value ranges from less than $1 \%$ to $15 \%$ approximately. In general, this variation may be tolerable. 
Table 3. Sensitivities of $\operatorname{As} \operatorname{Var}\left(\hat{y}_{q}\right)$ When $\sigma=1.0$ with $K=2$

\begin{tabular}{|c|c|c|c|c|c|c|c|}
\hline$P_{u}$ & $P_{h}$ & & & & & & \\
\hline \multirow[t]{40}{*}{0.0001} & \multirow[t]{8}{*}{0.99} & $\tilde{P}_{u} / \tilde{P}_{h}$ & 0.9700 & 0.9800 & 0.990 & 0.995 & 0.9990 \\
\hline & & 0.00001 & 1.1150 & 1.1014 & 1.0861 & 1.0691 & 1.0519 \\
\hline & & 0.00003 & 1.0440 & 1.0361 & 1.0248 & 1.0192 & 1.0107 \\
\hline & & 0.00005 & 1.0208 & 1.0155 & 1.0085 & 1.0056 & 1.0034 \\
\hline & & 0.00010 & 1.0026 & 1.0011 & 1 & 1.0008 & 1.0069 \\
\hline & & 0.00020 & 1.0057 & 1.0074 & 1.0107 & 1.0151 & 1.0300 \\
\hline & & 0.00030 & 1.0200 & 1.0238 & 1.0296 & 1.0364 & 1.0568 \\
\hline & & 0.00050 & 1.0564 & 1.0588 & 1.0679 & 1.0823 & 1.1055 \\
\hline & \multirow[t]{8}{*}{0.90} & $\tilde{P}_{u} / \tilde{P}_{h}$ & 0.7000 & 0.8000 & 0.900 & 0.950 & 0.9900 \\
\hline & & 0.00001 & 1.1097 & 1.1007 & 1.0823 & 1.0638 & 1.0446 \\
\hline & & 0.00003 & 1.0393 & 1.0341 & 1.0243 & 1.0181 & 1.0114 \\
\hline & & 0.00005 & 1.0169 & 1.0149 & 1.0087 & 1.0058 & 1.0067 \\
\hline & & 0.00010 & 1.0031 & 1.0014 & 1 & 1.0015 & 1.0126 \\
\hline & & 0.00020 & 1.0123 & 1.0087 & 1.0103 & 1.0160 & 1.0361 \\
\hline & & 0.00030 & 1.0324 & 1.0274 & 1.0279 & 1.0360 & 1.0618 \\
\hline & & 0.00050 & 1.0774 & 1.0658 & 1.0669 & 1.0784 & 1.1073 \\
\hline & \multirow[t]{8}{*}{0.50} & $\tilde{P}_{u} / \tilde{P}_{h}$ & 0.3000 & 0.400 & 0.500 & 0.6000 & 0.7000 \\
\hline & & 0.00001 & 1.0652 & 1.0794 & 1.0888 & 1.0923 & 1.0948 \\
\hline & & 0.00003 & 1.0124 & 1.0206 & 1.0279 & 1.0299 & 1.0347 \\
\hline & & 0.00005 & 1.0017 & 1.0061 & 1.0102 & 1.0133 & 1.0147 \\
\hline & & 0.00010 & 1.0047 & 1.0008 & 1 & 1.0004 & 1.0015 \\
\hline & & 0.00020 & 1.0365 & 1.0208 & 1.0114 & 1.0075 & 1.0061 \\
\hline & & 0.00030 & 1.0737 & 1.0474 & 1.0325 & 1.0233 & 1.0203 \\
\hline & & 0.00050 & 1.1471 & 1.1036 & 1.0769 & 1.0620 & 1.0533 \\
\hline & \multirow[t]{8}{*}{0.10} & $\tilde{P}_{u} / \tilde{P}_{h}$ & 0.0600 & 0.080 & 0.100 & 0.1200 & 0.1400 \\
\hline & & 0.00001 & 1.0826 & 1.1084 & 1.1267 & 1.1459 & 1.1601 \\
\hline & & 0.00003 & 1.0149 & 1.0278 & 1.0391 & 1.0520 & 1.0599 \\
\hline & & 0.00005 & 1.0013 & 1.0072 & 1.0146 & 1.0226 & 1.0299 \\
\hline & & 0.00010 & 1.0099 & 1.0016 & 1 & 1.0012 & 1.0031 \\
\hline & & 0.00020 & 1.0644 & 1.0340 & 1.0194 & 1.0101 & 1.0047 \\
\hline & & 0.00030 & 1.1298 & 1.0814 & 1.0524 & 1.0342 & 1.0234 \\
\hline & & 0.00050 & 1.2671 & 1.1790 & 1.1301 & 1.0968 & 1.0718 \\
\hline & \multirow[t]{8}{*}{0.01} & $\tilde{P}_{u} / \tilde{P}_{h}$ & 0.0060 & 0.008 & 0.010 & 0.0120 & 0.0140 \\
\hline & & 0.00001 & 1.1685 & 1.2199 & 1.2604 & 1.2978 & 1.3306 \\
\hline & & 0.00003 & 1.0312 & 1.0579 & 1.0843 & 1.1092 & 1.1300 \\
\hline & & 0.00005 & 1.0024 & 1.0147 & 1.0312 & 1.0478 & 1.0632 \\
\hline & & 0.00010 & 1.0232 & 1.0042 & 1 & 1.0024 & 1.0076 \\
\hline & & 0.00020 & 1.1744 & 1.0869 & 1.0465 & 1.0232 & 1.0110 \\
\hline & & 0.00030 & 1.3942 & 1.2218 & 1.1359 & 1.0869 & 1.0561 \\
\hline & & 0.00050 & 1.8871 & 1.5968 & 1.3891 & 1.2749 & 1.1993 \\
\hline \multirow[t]{8}{*}{0.0010} & \multirow[t]{8}{*}{0.99} & $\tilde{P}_{u} / \tilde{P}_{h}$ & 0.9700 & 0.980 & 0.990 & 0.9950 & 0.9990 \\
\hline & & 0.00010 & 1.1637 & 1.1553 & 1.1323 & 1.1190 & 1.0925 \\
\hline & & 0.00030 & 1.0580 & 1.0501 & 1.0413 & 1.0349 & 1.0237 \\
\hline & & 0.00050 & 1.0238 & 1.0207 & 1.0154 & 1.0103 & 1.0074 \\
\hline & & 0.00100 & 1.0020 & 1.0007 & 1 & 1.0005 & 1.0048 \\
\hline & & 0.00200 & 1.0140 & 1.0146 & 1.0183 & 1.0228 & 1.0343 \\
\hline & & 0.00300 & 1.0439 & 1.0455 & 1.0519 & 1.0557 & 1.0716 \\
\hline & & 0.00500 & 1.1153 & 1.1181 & 1.1232 & 1.1332 & 1.1504 \\
\hline
\end{tabular}


Table 3. Continued

\begin{tabular}{|c|c|c|c|c|c|c|c|}
\hline$P_{u}$ & $P_{h}$ & & & & & & \\
\hline & 0.90 & $\tilde{P}_{u} / \tilde{P}_{h}$ & 0.7000 & 0.800 & 0.900 & 0.9500 & 0.9900 \\
\hline & & 0.00010 & 1.1514 & 1.1484 & 1.1342 & 1.1129 & 1.0873 \\
\hline & & 0.00030 & 1.0455 & 1.0464 & 1.0422 & 1.0349 & 1.0259 \\
\hline & & 0.00050 & 1.0163 & 1.0178 & 1.0152 & 1.0115 & 1.0112 \\
\hline & & 0.00100 & 1.0029 & 1.0011 & 1 & 1.0009 & 1.0085 \\
\hline & & 0.00200 & 1.0316 & 1.0232 & 1.0195 & 1.0214 & 1.0348 \\
\hline & & 0.00300 & 1.0792 & 1.0596 & 1.0510 & 1.0532 & 1.0700 \\
\hline & & 0.00500 & 1.1836 & 1.1477 & 1.1287 & 1.1264 & 1.1390 \\
\hline & 0.50 & $\tilde{P}_{u} / \tilde{P}_{h}$ & 0.3000 & 0.400 & 0.500 & 0.6000 & 0.7000 \\
\hline & & 0.00010 & 1.1067 & 1.1324 & 1.1540 & 1.1641 & 1.1730 \\
\hline & & 0.00030 & 1.0196 & 1.0345 & 1.0476 & 1.0591 & 1.0644 \\
\hline & & 0.00050 & 1.0021 & 1.0090 & 1.0174 & 1.0244 & 1.0300 \\
\hline & & 0.00100 & 1.0121 & 1.0019 & 1 & 1.0012 & 1.0036 \\
\hline & & 0.00200 & 1.0839 & 1.0435 & 1.0229 & 1.0126 & 1.0070 \\
\hline & & 0.00300 & 1.1711 & 1.1032 & 1.0641 & 1.0414 & 1.0298 \\
\hline & & 0.00500 & 1.3720 & 1.2365 & 1.1648 & 1.1189 & 1.0882 \\
\hline & 0.10 & $\tilde{P}_{u} / \tilde{P}_{h}$ & 0.0600 & 0.080 & 0.100 & 0.1200 & 0.1400 \\
\hline & & 0.00010 & 1.1677 & 1.2187 & 1.2588 & 1.2957 & 1.3208 \\
\hline & & 0.00030 & 1.0304 & 1.0567 & 1.0829 & 1.1075 & 1.1279 \\
\hline & & 0.00050 & 1.0025 & 1.0151 & 1.0302 & 1.0465 & 1.0639 \\
\hline & & 0.00100 & 1.0234 & 1.0043 & 1 & 1.0024 & 1.0077 \\
\hline & & 0.00200 & 1.1742 & 1.0883 & 1.0455 & 1.0224 & 1.0104 \\
\hline & & 0.00300 & 1.3917 & 1.2221 & 1.1355 & 1.0861 & 1.0552 \\
\hline & & 0.00500 & 1.9168 & 1.5895 & 1.3866 & 1.2676 & 1.1925 \\
\hline \multirow[t]{24}{*}{0.010} & 0.99 & $\tilde{P}_{u} / \tilde{P}_{h}$ & 0.9700 & 0.980 & 0.990 & 0.9950 & 0.9990 \\
\hline & & 0.00100 & 1.2793 & 1.2629 & 1.2433 & 1.2272 & 1.2000 \\
\hline & & 0.00300 & 1.0902 & 1.0856 & 1.0763 & 1.0721 & 1.0605 \\
\hline & & 0.00500 & 1.0345 & 1.0318 & 1.0284 & 1.0245 & 1.0210 \\
\hline & & 0.01000 & 1.0011 & 1.0004 & 1 & 1.0003 & 1.0026 \\
\hline & & 0.02000 & 1.0414 & 1.0402 & 1.0381 & 1.0382 & 1.0417 \\
\hline & & 0.03000 & 1.1253 & 1.1160 & 1.1119 & 1.1080 & 1.1052 \\
\hline & & 0.05000 & 1.3358 & 1.3131 & 1.2929 & 1.2794 & 1.2603 \\
\hline & 0.90 & $\tilde{P}_{u} / \tilde{P}_{h}$ & 0.7000 & 0.800 & 0.900 & 0.9500 & 0.9900 \\
\hline & & 0.00100 & 1.2457 & 1.2559 & 1.2527 & 1.2394 & 1.2095 \\
\hline & & 0.00300 & 1.0637 & 1.0767 & 1.0821 & 1.0798 & 1.0714 \\
\hline & & 0.00500 & 1.0171 & 1.0245 & 1.0292 & 1.0302 & 1.0313 \\
\hline & & 0.01000 & 1.0086 & 1.0020 & 1 & 1.0008 & 1.0057 \\
\hline & & 0.02000 & 1.1096 & 1.0678 & 1.0411 & 1.0332 & 1.0320 \\
\hline & & 0.03000 & 1.2691 & 1.1829 & 1.1229 & 1.0988 & 1.0865 \\
\hline & & 0.05000 & 1.7033 & 1.4878 & 1.3327 & 1.2735 & 1.2196 \\
\hline & 0.50 & $\tilde{P}_{u} / \tilde{P}_{h}$ & 0.3000 & 0.400 & 0.500 & 0.6000 & 0.7000 \\
\hline & & 0.00100 & 1.2190 & 1.2838 & 1.3305 & 1.3721 & 1.3991 \\
\hline & & 0.00300 & 1.0379 & 1.0733 & 1.1085 & 1.1397 & 1.1624 \\
\hline & & 0.00500 & 1.0021 & 1.0184 & 1.0393 & 1.0616 & 1.0837 \\
\hline & & 0.01000 & 1.0403 & 1.0069 & 1 & 1.0040 & 1.0129 \\
\hline & & 0.02000 & 1.2905 & 1.1338 & 1.0622 & 1.0265 & 1.0094 \\
\hline & & 0.03000 & 1.4966 & 1.3468 & 1.1921 & 1.1070 & 1.0590 \\
\hline & & 0.05000 & 1.4968 & 1.4967 & 1.4966 & 1.3568 & 1.2251 \\
\hline
\end{tabular}


Table 4. Sensitivities of $\operatorname{As} \operatorname{Var}\left(\hat{y}_{q}\right)$ When $\sigma=1.5$ with $K=2$

\begin{tabular}{|c|c|c|c|c|c|c|c|}
\hline$P_{u}$ & $P_{h}$ & & & & & & \\
\hline \multirow[t]{40}{*}{0.0001} & \multirow[t]{8}{*}{0.99} & $\tilde{P}_{u} / \tilde{P}_{h}$ & 0.9700 & 0.980 & 0.990 & 0.9950 & 0.9990 \\
\hline & & 0.00001 & 1.1315 & 1.1112 & 1.0903 & 1.0737 & 1.0481 \\
\hline & & 0.00003 & 1.0489 & 1.0406 & 1.0262 & 1.0181 & 1.0085 \\
\hline & & 0.00005 & 1.0248 & 1.0169 & 1.0098 & 1.0054 & 1.0027 \\
\hline & & 0.00010 & 1.0038 & 1.0012 & 1 & 1.0010 & 1.0084 \\
\hline & & 0.00020 & 1.0042 & 1.0070 & 1.0119 & 1.0185 & 1.0367 \\
\hline & & 0.00030 & 1.0191 & 1.0229 & 1.0315 & 1.0415 & 1.0666 \\
\hline & & 0.00050 & 1.0548 & 1.0616 & 1.0754 & 1.0903 & 1.1196 \\
\hline & \multirow[t]{8}{*}{0.90} & $\tilde{P}_{u} / \tilde{P}_{h}$ & 0.7000 & 0.800 & 0.900 & 0.9500 & 0.9900 \\
\hline & & 0.00001 & 1.1447 & 1.1235 & 1.0889 & 1.0646 & 1.0356 \\
\hline & & 0.00003 & 1.0582 & 1.0455 & 1.0266 & 1.0153 & 1.0082 \\
\hline & & 0.00005 & 1.0299 & 1.0208 & 1.0088 & 1.0047 & 1.0069 \\
\hline & & 0.00010 & 1.0068 & 1.0030 & 1 & 1.0022 & 1.0182 \\
\hline & & 0.00020 & 1.0074 & 1.0064 & 1.0111 & 1.0216 & 1.0500 \\
\hline & & 0.00030 & 1.0220 & 1.0225 & 1.0317 & 1.0444 & 1.0807 \\
\hline & & 0.00050 & 1.0597 & 1.0620 & 1.0729 & 1.0908 & 1.1384 \\
\hline & \multirow[t]{8}{*}{0.50} & $\tilde{P}_{u} / \tilde{P}_{h}$ & 0.3000 & 0.400 & 0.500 & 0.6000 & 0.7000 \\
\hline & & 0.00001 & 1.0880 & 1.0907 & 1.0924 & 1.0884 & 1.0790 \\
\hline & & 0.00003 & 1.0232 & 1.0271 & 1.0282 & 1.0264 & 1.0248 \\
\hline & & 0.00005 & 1.0056 & 1.0085 & 1.0106 & 1.0098 & 1.0092 \\
\hline & & 0.00010 & 1.0017 & 1.0003 & 1 & 1.0002 & 1.0010 \\
\hline & & 0.00020 & 1.0283 & 1.0171 & 1.0122 & 1.0117 & 1.0122 \\
\hline & & 0.00030 & 1.0620 & 1.0418 & 1.0339 & 1.0302 & 1.0304 \\
\hline & & 0.00050 & 1.1367 & 1.1005 & 1.0834 & 1.0731 & 1.0689 \\
\hline & \multirow[t]{8}{*}{0.10} & $\tilde{P}_{u} / \tilde{P}_{h}$ & 0.0600 & 0.080 & 0.100 & 0.1200 & 0.1400 \\
\hline & & 0.00001 & 1.0892 & 1.1147 & 1.1269 & 1.1448 & 1.1518 \\
\hline & & 0.00003 & 1.0176 & 1.0287 & 1.0396 & 1.0490 & 1.0592 \\
\hline & & 0.00005 & 1.0021 & 1.0077 & 1.0150 & 1.0208 & 1.0274 \\
\hline & & 0.00010 & 1.0082 & 1.0014 & 1 & 1.0008 & 1.0024 \\
\hline & & 0.00020 & 1.0604 & 1.0333 & 1.0191 & 1.0113 & 1.0056 \\
\hline & & 0.00030 & 1.1248 & 1.0776 & 1.0522 & 1.0364 & 1.0255 \\
\hline & & 0.00050 & 1.2679 & 1.1793 & 1.1305 & 1.1009 & 1.0788 \\
\hline & \multirow[t]{8}{*}{0.01} & $\tilde{P}_{u} / \tilde{P}_{h}$ & 0.0060 & 0.008 & 0.010 & 0.0120 & 0.0140 \\
\hline & & 0.00001 & 1.1716 & 1.2230 & 1.2634 & 1.2941 & 1.3260 \\
\hline & & 0.00003 & 1.0323 & 1.0593 & 1.0858 & 1.1075 & 1.1278 \\
\hline & & 0.00005 & 1.0027 & 1.0154 & 1.0305 & 1.0467 & 1.0618 \\
\hline & & 0.00010 & 1.0226 & 1.0040 & 1 & 1.0022 & 1.0079 \\
\hline & & 0.00020 & 1.1741 & 1.0887 & 1.0460 & 1.0240 & 1.0116 \\
\hline & & 0.00030 & 1.3900 & 1.2217 & 1.1385 & 1.0888 & 1.0576 \\
\hline & & 0.00050 & 1.8843 & 1.5996 & 1.3954 & 1.2753 & 1.2030 \\
\hline \multirow[t]{8}{*}{0.0010} & \multirow[t]{8}{*}{0.99} & $\tilde{P}_{u} / \tilde{P}_{h}$ & 0.9700 & 0.980 & 0.990 & 0.9950 & 0.9990 \\
\hline & & 0.00010 & 1.1791 & 1.1582 & 1.1359 & 1.1177 & 1.0880 \\
\hline & & 0.00030 & 1.0624 & 1.0544 & 1.0427 & 1.0337 & 1.0209 \\
\hline & & 0.00050 & 1.0271 & 1.0219 & 1.0149 & 1.0101 & 1.0061 \\
\hline & & 0.00100 & 1.0023 & 1.0009 & 1 & 1.0007 & 1.0054 \\
\hline & & 0.00200 & 1.0124 & 1.0147 & 1.0203 & 1.0247 & 1.0384 \\
\hline & & 0.00300 & 1.0417 & 1.0463 & 1.0526 & 1.0593 & 1.0786 \\
\hline & & 0.00500 & 1.1190 & 1.1218 & 1.1317 & 1.1417 & 1.1639 \\
\hline
\end{tabular}


Table 4. Continued

\begin{tabular}{|c|c|c|c|c|c|c|c|}
\hline$P_{u}$ & $P_{h}$ & & & & & & \\
\hline & 0.90 & $\tilde{P}_{u} / \tilde{P}_{h}$ & 0.7000 & 0.800 & 0.900 & 0.9500 & 0.9900 \\
\hline & & 0.00010 & 1.1862 & 1.1716 & 1.1355 & 1.1136 & 1.0762 \\
\hline & & 0.00030 & 1.0657 & 1.0577 & 1.0421 & 1.0320 & 1.0203 \\
\hline & & 0.00050 & 1.0287 & 1.0233 & 1.0156 & 1.0104 & 1.0079 \\
\hline & & 0.00100 & 1.0038 & 1.0016 & 1 & 1.0014 & 1.0110 \\
\hline & & 0.00200 & 1.0239 & 1.0183 & 1.0206 & 1.0249 & 1.0455 \\
\hline & & 0.00300 & 1.0670 & 1.0551 & 1.0563 & 1.0621 & 1.0833 \\
\hline & & 0.00500 & 1.1677 & 1.1433 & 1.1348 & 1.1425 & 1.1650 \\
\hline & 0.50 & $\tilde{P}_{u} / \tilde{P}_{h}$ & 0.3000 & 0.400 & 0.500 & 0.6000 & 0.7000 \\
\hline & & 0.00010 & 1.1333 & 1.1476 & 1.1555 & 1.1569 & 1.1515 \\
\hline & & 0.00030 & 1.0292 & 1.0427 & 1.0498 & 1.0539 & 1.0548 \\
\hline & & 0.00050 & 1.0050 & 1.0120 & 1.0173 & 1.0216 & 1.0245 \\
\hline & & 0.00100 & 1.0073 & 1.0014 & 1 & 1.0005 & 1.0020 \\
\hline & & 0.00200 & 1.0716 & 1.0391 & 1.0232 & 1.0160 & 1.0123 \\
\hline & & 0.00300 & 1.1603 & 1.0978 & 1.0684 & 1.0502 & 1.0403 \\
\hline & & 0.00500 & 1.3641 & 1.2385 & 1.1703 & 1.1314 & 1.1067 \\
\hline & 0.10 & $\tilde{P}_{u} / \tilde{P}_{h}$ & 0.0600 & 0.080 & 0.100 & 0.1200 & 0.1400 \\
\hline & & 0.00010 & 1.1788 & 1.2247 & 1.2637 & 1.2926 & 1.3158 \\
\hline & & 0.00030 & 1.0344 & 1.0618 & 1.0857 & 1.1066 & 1.1262 \\
\hline & & 0.00050 & 1.0031 & 1.0163 & 1.0317 & 1.0460 & 1.0605 \\
\hline & & 0.00100 & 1.0227 & 1.0039 & 1 & 1.0023 & 1.0073 \\
\hline & & 0.00200 & 1.1726 & 1.0885 & 1.0470 & 1.0246 & 1.0119 \\
\hline & & 0.00300 & 1.3951 & 1.2217 & 1.1369 & 1.0891 & 1.0594 \\
\hline & & 0.00500 & 1.9034 & 1.5997 & 1.3957 & 1.2772 & 1.2031 \\
\hline \multirow[t]{24}{*}{0.010} & 0.99 & $\tilde{P}_{u} / \tilde{P}_{h}$ & 0.9700 & 0.980 & 0.990 & 0.9950 & 0.9990 \\
\hline & & 0.00100 & 1.2811 & 1.2653 & 1.2405 & 1.2195 & 1.1888 \\
\hline & & 0.00300 & 1.0940 & 1.0861 & 1.0774 & 1.0705 & 1.0567 \\
\hline & & 0.00500 & 1.0349 & 1.0323 & 1.0274 & 1.0237 & 1.0188 \\
\hline & & 0.01000 & 1.0009 & 1.0003 & 1 & 1.0002 & 1.0022 \\
\hline & & 0.02000 & 1.0426 & 1.0412 & 1.0384 & 1.0381 & 1.0427 \\
\hline & & 0.03000 & 1.1260 & 1.1195 & 1.1143 & 1.1093 & 1.1079 \\
\hline & & 0.05000 & 1.3525 & 1.3262 & 1.3025 & 1.2862 & 1.2684 \\
\hline & 0.90 & $\tilde{P}_{u} / \tilde{P}_{h}$ & 0.7000 & 0.800 & 0.900 & 0.9500 & 0.9900 \\
\hline & & 0.00100 & 1.2851 & 1.2779 & 1.2576 & 1.2311 & 1.1924 \\
\hline & & 0.00300 & 1.0802 & 1.0863 & 1.0806 & 1.0749 & 1.0647 \\
\hline & & 0.00500 & 1.0253 & 1.0297 & 1.0302 & 1.0276 & 1.0257 \\
\hline & & 0.01000 & 1.0063 & 1.0016 & 1 & 1.0008 & 1.0053 \\
\hline & & 0.02000 & 1.1014 & 1.0670 & 1.0435 & 1.0368 & 1.0358 \\
\hline & & 0.03000 & 1.2641 & 1.1820 & 1.1292 & 1.1060 & 1.0936 \\
\hline & & 0.05000 & 1.7269 & 1.5033 & 1.3511 & 1.2902 & 1.2328 \\
\hline & 0.50 & $\tilde{P}_{u} / \tilde{P}_{h}$ & 0.3000 & 0.400 & 0.500 & 0.6000 & 0.7000 \\
\hline & & 0.00100 & 1.2504 & 1.2979 & 1.3346 & 1.3580 & 1.3728 \\
\hline & & 0.00300 & 1.0469 & 1.0823 & 1.1087 & 1.1312 & 1.1476 \\
\hline & & 0.00500 & 1.0042 & 1.0211 & 1.0410 & 1.0587 & 1.0744 \\
\hline & & 0.01000 & 1.0360 & 1.0058 & 1 & 1.0032 & 1.0098 \\
\hline & & 0.02000 & 1.2945 & 1.1349 & 1.0642 & 1.0296 & 1.0127 \\
\hline & & 0.03000 & 1.4657 & 1.3600 & 1.1972 & 1.1148 & 1.0672 \\
\hline & & 0.05000 & 1.4659 & 1.4658 & 1.4657 & 1.3808 & 1.2443 \\
\hline
\end{tabular}




\section{Conclusions}

Even through a lot of work has been done on optimal ALT plans, the computational techniques and results concerning asymptotically optimal ALT plans for Burr type X with log-linear model are new. In this paper, we have discussed optimal ALT plans for minimizing $A s \operatorname{Var}\left(\hat{y}_{q}\right)$ under the assumptions of Burr type $\mathrm{X}$ distribution, periodic inspection, and Type I censoring with log-linear model. We have derived the optimal allocation of units for two stress levels using Lagrange multipliers technique.

In optimality results, we have indicated various patterns of optimal plans and shown that the number of inspections need not be large and the plan is insensitive to misspecification of guessed failure probabilities at the design and high stress levels. We have also observed that the schemes with equally spaced inspection times at each stress level are administratively convenient and statistically optimal. We conclude that the Burr type X failure model is widely and quit effectively lifetime distribution for ALT. Finally, we have used an example to illustrate the planning of an ALT.

\section{Acknowledgements}

The authors are grateful to the Editor in Chief and the Reviewers for their valuable comments and suggestions to improve the manuscript.

\section{References}

[1] Ahmad, N. (2010). Designing Accelerated Life Tests for Generalized Exponential Distribution with Log-linear Model. International Journal of Reliability and Safety, Vol. 4 (2/3), 238 - 264.

[2] Ahmad, K.E., Fakhry, M.E., and Jaheen, Z.F. (1997). Empirical Bayes Estimation of $P(Y<X)$ and Characterization of Burr-type X Model. Journal of Statistical Planning and Inference, 64, 297-308.

[3] Ahmad, N., and Islam, A. (1996). Optimal Accelerated Life Designs for Burr Type XII Distributions Under Periodic Inspection and Type I Censoring. Naval Research Logistic, 43, 1049-1077.

[4] Ahmad, N., Islam, A., Kumar, R., and Tuteja, R.K. (1994). Optimal Design of Accelerated Life Test Plans Under Periodic Inspection and Type I Censoring: The Case of Rayleigh Failure Law. South African Statistical Journal, 28, 27-35.

[5] Ahmad, N., Khan, M. G. M., Quadri, S. M. K. and Kumar, M. (2009). Modelling and Analysis of Software Reliability with Burr Type X Testing-Effort and Release-Time Determination. Journal of Modelling in Management, Vol. 4 (1), 28 - 54.

[6] Ahmad, N., Quadri, S. M. K., and Choudhary, N. (2006). Design of Accelerated life Tests for Periodic Inspection with Burr Type III distributions: Models, Assumptions, and Applications. Journal of Applied Statistical Science, 15 (2), 161-179.

[7] Burr, I. W. (1942). Cumulative Frequency Distribution. Annals of Mathematical Statistics, 13, 215232.

[8] Chernoff, H. (1953). Locally Optimal Designs for Estimating Parameters. Annals of Mathematical Statistics, 24, 586-602.

[9] Chernoff, H. (1962). Optimal Accelerated Life Designs for Estimation. Technometrics, 4, 381-408.

[10] Ehrenfeld, S. (1962). Some Experimental Design Problems in Attribute Life Testing. Journal of American Statistical Association, 57, 668-679. 
[11] Islam, A., and Ahmad, N. (1994). Optimal Design of Accelerated Life Tests for the Weibull Distribution under Periodic Inspection and Type I Censoring. Microelectronics Reliability, 34, 14591468 .

[12] Jaheen, Z. F. (1996). Empirical Bayes estimation of the Reliability and Failure rate Functions of the Burr Type X Failure Model. Journal of Applied Statistical Science, 3, 281-288.

[13] Kundu, D., and Raqab, M. Z. (2005). Generalized Rayleigh Distribution: Different Methods of Estimations. Computational Statistics and Data Analysis, 49, 187-200.

[14] Meeker, W. Q. (1984). A Comparison of Accelerated Life Test Plans for Weibull and lognormal Distribution and Type I Censoring. Technometrics, 26, 157-171.

[15] Meeker, W. Q. (1986). Planning Life Tests in which Units are Inspected for Failure. IEEE Transactions on Reliability, R-35, 571-578.

[16] Meeker, W. Q., and Escobar, L. A. (1993). A Review of Recent Research and Current Issues in Accelerated Testing. International Statistical Review, 61, 147-168.

[17] Meeker, W. Q., and Escobar, L. A. (1998). Statistical Methods for Reliability Data. John Wiley and Sons, New York.

[18] Meeker, W. Q., and Nelson, W. (1975). Optimum Accelerated Life Tests for the Weibull and Extreme value Distributions. IEEE Transactions on Reliability, R-24, 321-332.

[19] Nelson, W. (1990). Accelerated Testing - Statistical Models, Test Plans, and data Analyses. John Wiley and Sons, New York.

[20] Nelson W. (2005). A Bibliography of Accelerated Test Plans. IEEE Transactions on Reliability, 54 (2), 194-197.

[21] Nelson W. (2005). A Bibliography of Accelerated Test Plans. IEEE Transactions on Reliability, 54 (3), 370-373.

[22] Nelson, W., and Kielpinski, T. J. (1976). Theory for Optimum Censored Accelerated Tests for Normal and Lognormal Life Distribution. Technometrics, 18, 105 -114.

[23] Nelson, W., and Meeker, W. Q. (1978). Theory for Optimum Accelerated Censored Life Tests for Weibull and Extreme Value Life Distributions. Technometrics, 20, 171-177.

[24] Park, J. W., and Yum, B. J. (1996). Optimal Design of Accelerated Life Tests with Two Stresses. Naval Research Logistic, 43, 863 -884.

[25] Raqab, M. Z. (1998). Order Statistics for the Burr Type X Model. Computer Mathematics and Applications, 36, 111-120.

[26] Raqab, M. Z., and Kundu, D. (2005). Comparison of Different Estimators of $P(Y<X)$ for a Scaled Burr Type X Distribution. Communications in Statistics-Simulation and Computation, 34, 465-483.

[27] Rao, C. R. (1973). Linear Statistical inference and its Applications. $2^{\text {nd }}$ ed., John Wiley and Sons, New York.

[28] Satawi, H. A., and Abu-Salih, M. S. (1991). Bayes Prediction Bounds for the Burr Type X Model. Communication in Statistics- Theory and Methods, 20, 2307-2330.

[29] Seo, S. K., and Yum, B. J. (1991). Accelerated Life Test Plans Under intermittent Inspection and Type-I Censoring: The Case of Weibull Failure Distribution. Naval Research Logistic, 38, 1-22.

[30] Surles, J. G., and Padgett, W. J. (1998). Inference for $P(Y<X)$ in the Burr Type X Model. Journal of Applied Statistical Science, 225-238.

[31] Surles, J. G., and Padgett, W. J. (2001). Inference for Reliability and Stress-Strength for a scaled Burr Type X Distribution. Lifetime Data Analysis, 7, 187-200.

[32] Surles, J. G., and Padgett, W. J. (2005). Some Properties of a Scaled Burr Type X Distribution. Journal of Statistical Planning and Inference, 128, 271-280.

Published by Atlantis Press

Copyright: the authors 
[33] Yang, G. (2007). Life Cycle Reliability Engineering. John Wiley and Sons, New Jersey.

[34] Yum, B. J., and Choi, S. C. (1989). Optimal Design of Accelerated Life Tests Under Periodic Inspection. Naval Research Logistic, 36, 779 -795.

\section{Appendix}

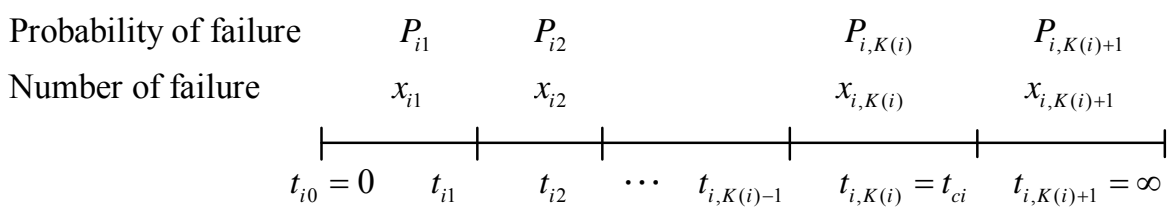

Figure 1. Structure of periodic inspection at the $i$ th stress level 